\title{
Ambient intimacy on Twitter
}

\author{
Ruoyun Lin ${ }^{1}$, Ana Levordashka ${ }^{2}$, Sonja Utz ${ }^{3}$ \\ 1,2,3 Leibniz-Institut für Wissensmedien, Tübingen, Germany \\ ${ }^{3}$ University of Tübingen, Tübingen, Germany
}

\begin{abstract}
Ambient intimacy refers to a feeling of closeness toward certain others developed mainly by following their status updates on social media. Previous researchers have demonstrated that it is possible to develop ambient awareness, that is, knowledge of others, after browsing social media, but it is still unclear whether and to what extent Twitter users also experience ambient intimacy, i.e., emotional closeness to others stemming from merely following them on Twitter. This paper is the first to theoretically distinguish the concept of ambient intimacy from ambient awareness. The paper investigates the degree to which Twitter users experience ambient awareness and intimacy. Moreover, we also examine the role of interaction history and message characteristics in this process. The results showed that Twitter users had experienced ambient intimacy but to a lesser degree than ambient awareness; the majority felt close to only a limited number of people in their Twitter network. Visibility of tweets and one-sided interaction with the target person predicted ambient intimacy. In addition, users were more likely to experience ambient intimacy toward a person when his or her tweets were perceived as more intimate, entertaining, and informative.
\end{abstract}

Keywords: Ambient intimacy; parasocial relationship; perceived closeness; self-disclosure; Twitter

\section{Introduction}

The term "ambient intimacy" was introduced in a blog post on the effects of Twitter use by Leisa Reichelt (2007); she argued that ambient intimacy is about "being able to keep in touch with people with a level of regularity and intimacy that you wouldn't usually have access to, because time and space conspire to make it impossible" and claimed that "knowing these details creates intimacy." Thus, ambient intimacy might be one of the processes that underlie the formation and maintenance of relationships on social media. Previous researchers have shown that social media use can strengthen weaker relationships (Ellison, Steinfield, \& Lampe, 2007). The majority of studies on social media use and relationships have been conducted on Facebook (Buechel \& Berger, 2016), where people often know their "friends" face-to-face. This makes it difficult to determine which effects stem from social media use and which are due to offline interaction. To shed some of the first light on the prevalence and predictors of ambient intimacy, we focus on Twitter because following strangers is more common on Twitter than on Facebook or business networks (Utz, 2015a). Perceived closeness with people know primarily via Twitter can thus be attributed to tweets and not to offline interactions.

The social media platform Twitter constantly updates users with a stream of short messages ranging from mundane to breaking news. Twitter enables users to post 140-character updates, "tweets," to a network of 
followers, and users can follow various accounts/users on Twitter. These networks can be asymmetric. Most users use Twitter not only to keep updated with their offline contacts but also to receive information from various celebrities and strangers in whom the users are interested. By regularly reading a person's status updates, individuals are able to get acquainted with the daily routine of one another and might even build (imaginary) close relationships with someone they have never met in person.

Related to ambient intimacy is the concept "ambient awareness" (Levordashka \& Utz, 2016; Thompson, 2008). The word "ambient" addresses the peripheral nature of these processes: Social media users are likely to develop an awareness of others or have an intimate feeling toward others even without focused attention (Levordashka \& Utz, 2016). We conceptualize ambient awareness as a cognitive process, the knowledge of others' activities created through constant and regular reception and/or interaction through social media (Kaplan, 2012). Ambient awareness refers to the feeling of knowing others via social media, while ambient intimacy, as an emotional process, addresses the feeling of closeness toward certain others on social media. We assume that a feeling of ambient intimacy can be developed based on ambient awareness, but ambient intimacy is not a necessary consequence of ambient awareness. Previous researchers have shown that Twitter users can develop ambient awareness toward others as a result of being exposed to others' broadcasting information on Twitter (Levordashka \& Utz, 2016), and this study aims to go one step further by exploring the phenomenon of ambient intimacy and the role of Twitter message characteristics in this process.

In the following sections, we introduce relevant concepts such as propinquity and parasocial relationships. We argue that ambient intimacy is a feeling of closeness (propinquity) developed in a peripheral way on social media, which can be one-sided such as in parasocial relationships.

We then study ambient intimacy on two levels. First, we aim to explore on a general level whether Twitter users experience ambient intimacy at all. Next, we examine on the target level whether they experience ambient intimacy with specific ties and examine the relationship of the frequency and content of tweets (message characteristics) with the target-specific ambient intimacy. In addition, we explore the relationship between ambient intimacy and awareness.

\section{Ambient Intimacy}

Science writer Thompson (2008) used the term "ambient intimacy" to describe the phenomenon in which people feel a sense of closeness with strangers that they follow for a while on Twitter. From our perspective, ambient intimacy is not restricted to illusionary relationships, with a stranger or a celebrity; it might also play an important role in keeping existing relationships such as with former classmates or colleagues, from fading. Therefore, similar to the definition of ambient awareness, we conceptualize ambient intimacy as a feeling of closeness that is developed in a peripheral way (through constant and regular reception and/or interaction through social media). Intimacy refers to a feeling of closeness, and ambient refers to the peripheral process of developing intimacy by aimless browsing and spontaneous interactions on social media. The concept of ambient intimacy shows some similarities with existing concepts such as "electronic propinquity" (Korzenny, 1978) and "parasocial relationship" (Horton \& Wohl, 1956).

Propinquity also means nearness. It was initially proposed by Festinger, Schachter, and Back (1950) to describe the fact that relationships are more likely to be formed between people who have a high propinquity and encounter each other more often.

Propinquity can mean more than just physical closeness. The advent of communication channels such as the telephone, instant messaging, and video conferencing has reduced the effects of (physical) propinquity. Virtual interaction can happen without the restraint of physical distance. This creates another notion, called electronic propinquity. It is conceptualized as "a continuum of the subjective perception an individual holds that he or she is functionally, if not physically, close to someone else" (Korzenny, 1978). In this regard, combined with the concept of ambient, ambient intimacy can also be treated as electronic propinquity unconsciously developed via social media. 
Another relevant concept is the phenomenon of parasocial relationships. It is characterized as long-term onesided illusionary intimacy that users develop toward media performers based on repeated encounters (Horton \& Wohl, 1956). Slightly different from parasocial relationship (PSR), parasocial interaction (PSI) refers to imaginative interactions with a media performer that are confined to media exposure. PSI is more short-term and occurs only during the exposure situation (Dibble, Hartmann, \& Rosaen, 2016).

Similar to the parasocial interaction, communication network on Twitter is often asymmetric. Twitter users can follow someone who does not necessarily follow back the users. By constantly reading a person's tweets, it might be possible to develop a feeling of closeness toward this person (Thompson, 2008). This resembles the one-sided relationships with media figures or fictive persons on TV shows described in the literature on parasocial relationships. One difference is that reading a person's tweets that are loosely embedded in news feeds could be less absorbing than watching an actor performing in a TV show, as tweets are usually short and mundane whereas TV shows are often vivid and involving. Another difference is that, unlike watching TV, Twitter actually offers the possibility for mutual interaction on the social media platform. However, in the case of interacting with a celebrity on Twitter, it is more likely to be one-sided interaction; that is, it is much more likely that a person likes or retweets tweets by a celebrity than the other way round.

We assume that ambient intimacy can be formed merely by reading others' social news on social media even without interactions online and offline. To avoid a confounding effect of face-to-face interactions, in this study, we mainly examine the experience of ambient intimacy toward those primarily encountered on Twitter. Because Twitter is an interactive medium that allows user to favorite, retweet, and @reply each other, we also take the interactions on Twitter into consideration in the following investigation.

Two levels of ambient intimacy were examined in this study: general and target level. General-level ambient intimacy refers to a peripheral feeling of closeness toward contacts on social media formed mainly through repetitive exposure, and target-level ambient intimacy refers to a feeling of (imaginary) closeness toward a specific target. We addressed the peripheral characteristic of the developing process (i.e., mainly through reading others' tweets) when we measured general-level ambient intimacy and controlled for interactions on Twitter when we analyzed target-level ambient intimacy.

\section{General Level Ambient Awareness vs. Intimacy}

Ambient awareness has received some attention from scholars, especially in the domain of enterprise social media. It has been shown that people can build a cognitive representation of who-knows-what in their company by regularly reading updates on a company-intern social media platform (Leonardi \& Meyer, 2015). Scholars also demonstrated that browsing tweets can lead to ambient awareness (Levordashka \& Utz, 2016). Although the phenomenon of ambient intimacy has been mentioned in blogs, news articles, and popular science books (Brinker, 2009; Reichelt, 2007; Thompson, 2008), it has not been scientifically and systematically examined yet. It remains unclear whether knowing what others are doing (ambient awareness) can help develop a feeling of closeness. We assume that ambient intimacy is a potential, but not necessary, consequence of ambient awareness, and therefore, we expect lower levels of ambient intimacy than of ambient awareness. Thus, we asked the research question and developed the hypothesis:

RQ: To what extent do users experience ambient intimacy by following others on Twitter?

H1: Ambient intimacy is less frequently experienced than ambient awareness on Twitter.

\section{Target-Level Ambient Intimacy and Its Predictors}

Message frequency (visibility) and interaction. Receiving more self-disclosure in general increases liking (Collins \& Miller, 1994). We also assume that receiving tweets regularly from others is helpful for developing ambient intimacy. According to the "mere exposure effect" (Zajonc, 1968), individuals tend to like things more when they have been exposed to the things more often. In the context of Twitter, mere exposure is determined by the visibility of a person's tweets instead of a person's tweeting frequency. With visibility, we mean the 
perceived frequency of tweets from a specific target; this might differ from actual frequency, for example, for people who live in different time zones. Therefore, we expected:

$\mathrm{H} 2$ : The visibility of the tweets from a target person is positively associated with target-level ambient intimacy.

In addition to being merely exposed to others' tweets, it is also possible to engage in one-sided interactions such as favorite, retweet, and reply to other's tweets on Twitter. Even though interacting with the target is not necessary to develop ambient intimacy by definition, we also assume that there is a positive correlation between the interaction with the target and ambient intimacy. According to the parasocial interaction literature, onesided interaction with a person is often observed when people view their favorite character on a TV show (Horton \& Wohl, 1956; Perse \& R. B. Rubin, 1989). Similarly, such one-sided interaction might also be a natural byproduct of ambient intimacy: Twitter users may be more likely to interact with targets the users feel close to, even without expecting a response from the targets. We posited the following hypothesis:

H3: Interaction with the target person on Twitter is positively associated with target-level ambient intimacy.

Disclosure intimacy. Tweets that involve self-disclosure can vary in disclosure depth, ranging from trivial or mundane (superficial) to intimate issues. However, the role of disclosure depth in developing closeness on social media is less clear than that in offline settings. In traditional offline research, revealing intimate information about oneself is often found to be helpful for relationship development (Altman \& Taylor, 1973). Recently, Rains, Brunner, and Oman (2014) showed that revealing a greater proportion of superficial self-disclosure via new communication technology, such as calling, texting, emailing, instant messaging, and using social media, is detrimental for relationship development as the technology may be treated by disclosure recipients as not valuable and a waste of time.

When it comes to broadcasting self-disclosure on social media, Bazarova (2012) found that intimate selfdisclosure in public might be treated as inappropriate and therefore reduced social attraction. Baruh and Cemalcilar (2015) found that intimate self-disclosure on Twitter had negative effects on interpersonal attraction, even though high-intimacy disclosure attracted more attention compared to low-intimacy disclosure. However, the authors' stimuli differed not only in the level of intimacy but also in the level of appropriateness. Thus, it cannot be determined whether lower interpersonal attraction was caused by high intimacy or low appropriateness.

We assume that in most cases Twitter users follow accounts they like and unfollow accounts that they do not like or perceive as inappropriate. If tweets from the target are mostly perceived as appropriate, then disclosure intimacy should have a positive effect on the development of ambient intimacy. We posited the following hypothesis:

H4: Perceived intimacy of the tweets from a target person is positively associated with target-level ambient intimacy (when controlling for the level of appropriateness).

Entertainment and information value. Messages on Twitter differ not only in degree of intimacy and appropriateness but also in how much information the messages can contain and how entertaining the messages are. How do the entertainment and information value influence the development of ambient intimacy? Recently, Utz (2015b) examined what types of self-disclosure on Facebook are more likely to increase a feeling of connection from a recipient's perspective. She found that disclosures that were intimate and entertaining were positively correlated with a higher feeling of connection on Facebook. Will similar results occur on Twitter, where most contacts are not offline friends and most tweets are pointless babble (Kelly, 2009)? Because humor and interaction enjoyment have a positive effect on relationship formation in offline contexts and when communicating via Skype with strangers (Sprecher, Treger, \& Wondra, 2012; Treger, Sprecher, \& Erber, 2013), we assumed that entertaining tweets would also have a positive effect in developing ambient intimacy. Thus, we posited the following: 
$\mathrm{H} 5$ : The perceived entertainment value of the tweets from a specific person is positively associated with target-level ambient intimacy.

Regarding the role of the perceived information value of tweets on closeness or ambient intimacy, we are not aware of any empirical study thus far. However, there is conceptual work from Miller (2008), who argued thatin the context of blogging-information has become a commodity that is used to build and maintain relationships. One could thus argue that perceived information value is also positively associated with targetlevel ambient intimacy. As getting information is one of the main motives for using Twitter (Johnson \& Yang, 2009), we assume that informative tweets are more likely to attract attention and that Twitter users who regularly send informative tweets are perceived as closer. We posited the following hypothesis:

H6: The perceived information value of the tweets from a specific person is positively associated with target-level ambient intimacy.

\section{Target-Level Ambient Awareness and Its Predictors}

We assume that certain criteria may be able to distinguish ambient intimacy from ambient awareness, such as the degree of liking, positive belief, or perceived similarity toward the target. For exploratory purposes, we would like to know whether certain message characteristics and interactions distinguish ambient intimacy from ambient awareness. For example, a certain style of tweets by the target may trigger liking and therefore prompt the development of ambient intimacy; once the disclosed information is perceived as not likable, ambient awareness might still be developed, but not ambient intimacy. In this study, we also explore the roles of predictors in predicting ambient awareness.

\section{Method}

\section{Procedure}

The setup was the same as in Levordashka and Utz's (2016) study. Twitter users were recruited as participants via an online panel (Tellwut); each participant was compensated $\$ 2$. They were first asked to provide informed consent and approve a request to access their Twitter profile. Then we showed the participants a random list of 100 Twitter users they followed and asked the participants to categorize at least 50 Twitter users into certain categories: (a) Twitter contacts (those who they encountered primarily on Twitter), (b) outside-Twitter contacts (those who they encountered primarily outside Twitter), (c) nonhuman contacts (such as organizations' Twitter accounts), and (d) unknown (if they are not able to categorize). Then we asked several general questions about the participants' general experience of ambient intimacy (participant-level questions). After that, a random Twitter profile (including name, profile picture, and Twitter handle), which had previously been categorized as a Twitter contacts that the participants encountered primarily on Twitter, was shown. We asked to what extent the participant was familiar with that target profile. If the participant answered not at all, then we showed him or her next profile that was randomly picked from his or her Twitter contacts. Otherwise, several target-level questions followed for that target profile, including questions about the feeling of closeness, parasocial reaction toward the target and perceived intimacy, appropriateness, information, and entertainment value of the tweets from that target. These target-level questions were presented repetitively after each qualified target, but no more than three times for each participant. At the end of the questionnaire, participant-level information such as their Twitter usage behavior and demographics were measured.

\section{Sample}

Two hundred and fifty-seven participants completed the questionnaire, but we dropped 78 participants who failed the attention check and one participant who used Twitter once a year or less. Therefore, 178 participants were left for the analysis. Among them, $60.67 \%$ were female, $64.04 \%$ did not have at least a bachelor's degree, and $38.20 \%$ were employed at that point. The mean age was 42 years $(S D=12.82)$. 


\section{Measures}

\section{Participant-level variables.}

General-level ambient awareness and intimacy: Experience. General experience of ambient awareness was measured with one item: "It is possible that when using Twitter, you develop awareness of the people whose updates you follow. Even if individual updates are short and mundane, together they might give you an idea of the person who posts them-what they are like, what they do, etc. Do you experience such general awareness of the people in your Twitter network and to what extent?" (Levordashka \& Utz, 2016). Participants were asked to respond on a continuous scale ranging from 1 (to no extent) to 10 (to a great extent). Similar to the question that measured general ambient awareness experience, general ambient intimacy experience was measured with an identical continuous scale: "It is possible that, by regularly reading tweets from a person, you feel emotionally close to the person even if you do not (often) meet the person offline. Do you experience such a general feeling of closeness with your Twitter network and to what extent?"

General-level ambient awareness and intimacy: Number of people. For ambient awareness, participants were asked for a rough estimation of how many people in their Twitter they have gotten to know mainly through others' posts; whereas for ambient intimacy, participants were asked for a rough estimation of how many people in their Twitter network they feel close to (mainly because of reading others' tweets). The number was measured with a 7-point ordinal scale $(0=$ not applicable, $1=$ one or two people, $2=$ several people, $3=$ more than several, $4=$ about half, $5=$ more than half, $6=$ almost everyone).

Twitter usage time, personality, and demographics. Twitter usage time was assessed by an estimation of hours spent on Twitter per week. We included need to belong as a control variable, as people with higher need to belong might be more willing to develop intimate feelings toward others. It was measured with a single-item question with a 7-point Likert scale (Nichols \& Webster, 2013). Basic demographic information, such as gender, age, and employment status, was also measured at the end of the questionnaire.

Attention checks. We also included a modified version of an instructional manipulation check to test whether the participants were attentive (Oppenheimer, Meyvis, \& Davidenko, 2009). We excluded all participants who failed this attention check from the analysis.

\section{Target-level variables.}

Target-level ambient awareness and intimacy. Target-level ambient awareness was measured with eight items, such as "XX's tweets allow me to get to know him/her at least somewhat" (Cronbach's a $=.82$ ) ( Levordashka, Lin, \& Utz, 2015). In line with our conceptualization of ambient intimacy, we measured target-level ambient intimacy by combining items on the feeling of closeness and parasocial interaction. ${ }^{1}$ The feeling of closeness (How close do you feel to XX?) was measured with a continuous scale ranging from 0 (not close at all) to 10 (very close). On the next page, we adapted 11 items from the PSI-Process Scale (Schramm \& Hartmann, 2008), which is a postexposure measurement depicting specific cognitive, affective, and behavioral aspects of parasocial reactions during the exposure situation. Example items were "I became aware of aspects of XX that I really liked or disliked," "If XX tweeted something sad, I felt bad as well; if XX tweeted something good, I felt good as well," and "Occasionally, I said something out loud on impulse after seeing his (her) post." All items were rated on a 7-point Likert scale.

Perceived message characteristics. Participants were asked to rate the target's tweets on the following dimensions on a 7-point semantic differential scale: inappropriate-appropriate, superficial-intimate; boringentertaining; not informative-informative.

Visibility and length of following. The visibility of the target's tweets was used as an indicator of message frequency. Participants were asked to rate how often they saw tweets from the target, given a categorical scale ranging from 0 (never) to 6 (all the time). We also asked how long the participant had followed the target as a control variable, with a scale ranging from 1 (less than a week) to 5 (more than a year). 
Interaction. We distinguished two directions of the interaction between the participant and the target on Twitter and measured them as follows: "How often do you interact with the target on Twitter (retweet RT, reply @, favorite tweets, or send direct messages)?" and "How often does the target interact with you (retweet RT, reply @, favorite tweets, or send direct messages)?" The scale ranged from 0 (never) to 7 (all the time).

Offline contact. To avoid situations in which participants developed a feeling of closeness because of offline meetings, we additionally asked the participants whether they had met the target face-to-face before. If they said yes, then we dropped these cases from the target-level analysis.

\section{Results}

\section{To What Extent Do Twitter Users Experience Ambient Intimacy?}

General-level ambient intimacy. In order to answer the research question and to compare the degree of ambient intimacy with the degree of ambient awareness, we first focused on the questions about general-level ambient awareness and intimacy. About $61.80 \%$ of participants indicated that they had some experience of ambient intimacy, and $76.41 \%$ of participants reported for the experience of ambient awareness (when the degree of experience is equal or larger than 4). The results indicated that ambient intimacy $(M=5.36, S D=2.47)$ was less commonly experienced by participants than ambient awareness $(M=6.37, S D=2.24), t(177)=7.32, p<$ .001 ; thus, $\mathrm{H} 1$ was supported.

Participants also indicated a larger number of people toward whom they had experienced ambient awareness $(M=2.37, S D=1.48)$ than that for ambient intimacy $(M=2.03, S D=1.61), t(177)=3.40, p<.001$. About $14 \%$ of participants had not experienced ambient intimacy at all and therefore chose not applicable for this question. Many of the participants (56.75\%) felt close to only one to several people in their Twitter network, and 29.22\% of the participants reported that they felt close to more than several people. Whereas for ambient awareness, only $6.18 \%$ of the participants chose not applicable, and $40.45 \%$ reported that they have gotten to know "more than several people" through Twitter. These results also supported H1, showing that the phenomenon of ambient intimacy is less commonly experienced by Twitter users compared to the phenomenon of ambient awareness.

Target-level ambient intimacy. If participants recognized the target profile as not totally unfamiliar, we also asked target-level ambient intimacy questions. Each participant reported up to three human targets. After the targets that the participants had met face-to-face before were excluded, 401 cases were left. Although we already filtered out those target profiles that participants were not familiar with, the participants still reported they did not feel close at all to the target in 62 cases (15.46\%). This is also in line with our understanding that ambient intimacy is not necessarily a natural consequence of ambient awareness.

\section{Target-Level Ambient Intimacy and Its Predictors}

We measured target-level ambient intimacy by integrating the scale of parasocial interaction with the measure of feeling of closeness. To test whether the current measure represented a valid single-factor construct, we ran a factor analysis using principal component analysis with direct oblimin rotation (see the results in Table 1). All reversed items were loaded into a second factor, which is probably an artifact factor due to the wording direction (Spector, Van Katwyk, Brannick, \& Chen, 1997). Because the items in the first factor are closer to what we intended to measure for ambient intimacy, we decided to drop the four items in the second factor. By standardizing the remaining eight items and then taking their numerical mean, we generated a measure for target-level ambient intimacy (Cronbach's $a=.87$ ). 
Table 1. Factor Loadings and Communalities Based on Principal Components Analysis with Oblimin Rotation for 11 Items Adapted from the PSI-Process Scale and One Item for Measuring Closeness.

\begin{tabular}{lcc}
\hline & $\begin{array}{c}\text { Ambient } \\
\text { intimacy }\end{array}$ & $\begin{array}{c}\text { Ambient } \\
\text { intimacy } \\
\text { (reversed) }\end{array}$ \\
\hline Sometimes I really loved XX for what (s)he posted. & .777 \\
How close do you feel to XX? & .760 \\
I became aware of aspects of XX that I really liked or disliked. & .753 \\
XX could be a friend of mine. & .743 \\
XX is likable. & .710 \\
Occasionally, I said something out loud on impulse after seeing his & .700 \\
(her) post. & .693 \\
XX tweeted something sad, I felt bad as well; if XX tweeted & & \\
something good, I felt good as well. & .673 \\
Every once in a while, I have thought about whether XX is similar or & \\
dissimilar to me. & & .754 \\
I demonstrated little empathy toward XX. & .685 \\
The feelings, which I observed XX go through, were not contagious. & .661 \\
I formed only a fleeting impression of XX. & -.379 & .614 \\
I do not feel the desire to react to XX's tweets. & & \\
\hline Note: $N=401$. Factor loadings <.3 are suppressed. &
\end{tabular}

Hypotheses testing. According to the hypotheses, the role of visibility, interaction with the target, and perceived message characteristics (intimacy, appropriateness, entertainment, and information value) were examined as key predictors of the phenomenon of ambient intimacy. The descriptive and correlational statistics are depicted in Table 2. In addition to those key predictors, we added promising control variables, including the length of following on Twitter, and four participant-level variables such as Twitter usage time, need to belong, age, and gender. Because all target-level questions were nested in participants, multilevel linear regressions were used for analysis. All variables were standardized before they were put into the multilevel linear regressions.

Table 2. Descriptive and Pearson's Correlation Statistics for Visibility, Interaction, and Perceived Message Characteristics.

\begin{tabular}{lllllllll}
\hline Variables & $\boldsymbol{M}$ & $\boldsymbol{S D}$ & $\mathbf{1}$ & $\mathbf{2}$ & $\mathbf{3}$ & $\mathbf{4}$ & $\mathbf{5}$ & $\mathbf{6}$ \\
\hline 1. Visibility & 3.02 & 1.38 & - & & & & & \\
2. Interaction with target & 2.69 & 1.57 & .63 & - & & & & \\
3. Interaction from target & 2.30 & 1.55 & .47 & .81 & - & & & \\
4. Perceived intimacy & 4.60 & 1.44 & .17 & .31 & .27 & - & & \\
5. Perceived appropriateness & 6.08 & 1.24 & .23 & .30 & .23 & .36 & - & \\
$\begin{array}{l}\text { 6. Perceived entertainment } \\
\text { value }\end{array}$ & 5.60 & 1.40 & .33 & .33 & .25 & .51 & .46 & - \\
$\begin{array}{l}\text { 7. Perceived information } \\
\text { value }\end{array}$ & 5.71 & 1.37 & .24 & .29 & .24 & .43 & .62 & .41 \\
\hline
\end{tabular}

Note: $N=401$. 
The results of the hypotheses testing can be found in Model 1 in Table 3 . The visibility of the tweets from the target was a significant predictor of ambient intimacy $(\beta=.181, z=5.45, p<.001)$; thus, $\mathrm{H} 2$ was supported. We investigated the interaction with the target person in two directions: the participant's interaction with the target and the target's interaction with the participant. The results were partially in line with H3: Only the participant's interaction with target was important in developing ambient intimacy $(\beta=.132, z=2.70, p=.007)$, but the target's interaction with the participant (interaction with the target) did not matter as much ( $\beta=.047, z=1.08, p=$ .281). Regarding perceived message characteristics, all three hypotheses $(\mathrm{H} 4-\mathrm{H} 6)$ were supported. As most tweets were perceived as appropriate $(M=6.08, S D=1.24)$ in the current sample, the perceived intimacy $(\beta=$ $.098, z=3.13, p=.002)$, entertainment value $(\beta=.206, z=6.81, p<.001)$, and information value $(\beta=.105, z=$ $3.26, p=.001$ ) were positively correlated with the development of target-level ambient intimacy.

Table 3. Results for Random-Effects Multilevel Linear Models.

\begin{tabular}{|c|c|c|c|c|c|c|}
\hline \multirow{2}{*}{ Target-level variables } & \multicolumn{2}{|c|}{$\begin{array}{l}\text { Target-level ambient } \\
\text { intimacy (Model 1) }\end{array}$} & \multicolumn{2}{|c|}{$\begin{array}{l}\text { Target-level ambient } \\
\text { awareness (Model 2) }\end{array}$} & \multicolumn{2}{|c|}{$\begin{array}{c}\text { Target-level } \\
\text { ambient intimacy } \\
\text { (Model 3) }\end{array}$} \\
\hline & & & & & & \\
\hline Ambient awareness & & & & & $.219 * \star \star$ & $(.03)$ \\
\hline Visibility & $.182 * \star *$ & $(.03)$ & $.259 * * *$ & $(.06)$ & $.124 * * *$ & (.03) \\
\hline $\begin{array}{l}\text { Interaction with } \\
\text { target }\end{array}$ & $.132 * \star$ & $(.05)$ & .102 & $(.09)$ & $.109 * \star$ & $(.05)$ \\
\hline $\begin{array}{l}\text { Interaction from } \\
\text { target }\end{array}$ & .047 & $(.04)$ & .016 & $(.08)$ & .044 & $(.04)$ \\
\hline Perceived intimacy & $.098 * *$ & $(.03)$ & .085 & $(.06)$ & $.082^{\star *}$ & $(.03)$ \\
\hline $\begin{array}{l}\text { Perceived } \\
\text { appropriateness }\end{array}$ & .011 & $(.03)$ & .018 & $(.06)$ & .006 & (.03) \\
\hline $\begin{array}{l}\text { Perceived } \\
\text { entertainment value }\end{array}$ & $.206 * \star \star$ & $(.03)$ & $.130 *$ & $(.05)$ & $.178^{* * *}$ & $(.03)$ \\
\hline $\begin{array}{l}\text { Perceived } \\
\text { information value }\end{array}$ & $.105^{\star \star}$ & $(.03)$ & $.168^{\star \star}$ & $(.06)$ & $.068 *$ & $(.03)$ \\
\hline Length of following & .012 & $(.03)$ & $.098 *$ & $(.05)$ & -.009 & $(.03)$ \\
\hline \multicolumn{7}{|c|}{ Participant-level variables } \\
\hline Twitter usage time & .028 & $(.04)$ & -.084 & $(.06)$ & .046 & $(.03)$ \\
\hline Need to belong & .026 & $(.03)$ & .011 & $(.06)$ & .023 & (.03) \\
\hline Age & -.024 & $(.03)$ & -.069 & $(.05)$ & -.009 & $(.03)$ \\
\hline Gender & -.025 & $(.03)$ & -.014 & $(.05)$ & -.023 & $(.03)$ \\
\hline Constant & .001 & $(.03)$ & -.011 & $(.05)$ & .004 & $(.03)$ \\
\hline$N$ & \multicolumn{2}{|c|}{398} & \multicolumn{2}{|c|}{398} & \multicolumn{2}{|c|}{398} \\
\hline Overall $R^{2}$ & \multicolumn{2}{|l|}{.56} & \multicolumn{2}{|c|}{.32} & \multicolumn{2}{|c|}{.62} \\
\hline
\end{tabular}

Note: Standardized coefficients are followed by standard errors in parentheses. Random effects models were preferred based on the results of the Hausman tests. Three cases were missing because of the missing values for Twitter usage time. ${ }^{*} p<.05 ;{ }^{* *} p<.01 ;{ }^{* *} p<.001$.

Post hoc analysis. We also argued that having ambient awareness is the first step in developing ambient intimacy, and some unique predictors may be able to distinguish ambient intimacy from ambient awareness. Though there was a high correlation (Pearson's $r=0.60$ ) between the target-level ambient awareness and intimacy, we explored the distinctive role of self-disclosure in predicting ambient intimacy by running two additional analyses (see Models 2 and 3 in Table 3). 
In Model 2, the same predictors of models were used to predict target-level ambient awareness. The overall variance $\left(R^{2}=.32\right)$ explained by the predictors was lower than that in Model $1\left(R^{2}=.56\right)$. Perceived disclosure intimacy and the participant's interaction with the target were no longer significant predictors for ambient awareness; instead, length of following became a better predictor. In Model 3, we added target-level ambient awareness as an additional predictor for ambient intimacy based on Model 1. We found that awareness is a significant predictor for ambient intimacy, and the results for the hypotheses testing still held.

A comparison across the three models indicated that there is a possibility that ambient awareness mediates the effects of visibility, entertainment value, and information value on ambient intimacy because the standardized coefficients were smaller when ambient awareness was also entered in the model. Perceived disclosure intimacy, however, was not a significant predictor of ambient awareness in Model 2. This could be a hint that perceived intimacy is a unique factor that predicts only ambient intimacy. Nevertheless, the differences between the standardized coefficients of perceived disclosure intimacy in these three models were small. More research is required to verify whether perceived disclosure intimacy is a unique predictor of ambient intimacy or not.

Another interesting result is that the coefficient of perceived entertainment value $(\beta=.206)$ in predicting ambient intimacy was larger than that $(\beta=.130)$ in predicting ambient awareness, whereas the coefficient of perceived information value $(\beta=.105)$ in predicting ambient intimacy was smaller than that $(\beta=.168)$ in predicting ambient awareness. This can be interpreted as message entertainment value could play a better role in predicting a feeling of closeness, but message information value is more important for predicting ambient awareness.

\section{Discussion}

This study examined the degree to which Twitter users experienced ambient intimacy on the general and target level and examined the role of predictors such as message characteristics and interaction history in explaining ambient intimacy at the target level. More important, the study explored the difference between ambient awareness and intimacy. An online survey was conducted with a sample of 178 Twitter users (mainly from North America). At the general level, the results showed that, compared to the degree of ambient awareness, users reported a lower level of ambient intimacy in this study, and many felt close to only a very small portion of contacts in their entire Twitter network. At the target level, the results showed that the frequency of seeing tweets from the target person and the one-sided interaction with the target person on Twitter predicted ambient intimacy. Target-level ambient intimacy was more likely to be developed when the target person's tweets were perceived as more intimate, entertaining, and informative.

\section{Theoretical Implications}

The results contributed to a better understanding of ambient intimacy and ambient awareness. These concepts have been introduced by journalists and science bloggers but have been rarely examined in empirical studies. By showing that people experience ambient intimacy, but to a lesser degree and a smaller proportion of their Twitter network than ambient awareness, we demonstrated that ambient awareness is a necessary, but not sufficient, precondition for ambient intimacy. The higher correlation of ambient intimacy with intimacy of selfdisclosure and the higher correlation of ambient awareness with the information value of tweets support our conceptualization of ambient intimacy as an emotional process and of ambient awareness as a cognitive process. The latter has been demonstrated in recent studies in organizational contexts, indicating that regularly skimming updates in enterprise social networks helps people create a cognitive representation of who-knowswhat in their network (Leonardi \& Meyer, 2015).

Researchers have shown that intense use of social media can lead to a general sense of belonging (Chen, 2011) and social connectedness (Grieve, Indian, Witteveen, Tolan, \& Marrington, 2013; Riedl, Köbler, Goswami, \& Krcmar, 2013). However, researchers have rarely examined the phenomenon of ambient intimacy, i.e., a peripheral feeling of closeness developed via following others on social media. Ellison and her colleagues (2007) showed that using social network sites (SNSs) such as Facebook helps mainly in strengthening bonds that have weaker ties, but it was unclear how exactly this worked. Our results show that simply regularly skimming posts 
by others, even strangers, can create a feeling of closeness in some cases. One could assume that this mechanism plays an even more important role when it comes to preventing existing ties from fading.

Regarding the development of ambient intimacy, we found that users are more likely to develop target-level ambient intimacy if they see tweets from the target more often (higher visibility). However, the length of following did not play a role in predicting ambient intimacy when visibility was taken into consideration. This result indicates that ambient intimacy can develop quickly and is determined more by frequent exposure than by exposure over long periods of time. These results also have methodological implications for studies on parasocial interaction. Prior studies on the influence of time on parasocial interaction with TV characters revealed inconsistent findings, depending on whether length of viewing was operationalized as frequency of viewing or length of acquaintance (Auter \& Palmgreen, 2000; Perse \& R. B. Rubin, 1989; R. B. Rubin \& McHugh, 1987). It seems that exposure (visibility and frequency of viewing) is a better predictor than length of acquaintance when it comes to relationship formation.

More importantly, the results also showed that initiating more interactions with the target was positively associated with the development of ambient intimacy whereas receiving interaction from the target was not a determining factor for developing ambient intimacy in this sample. This is interesting because the interactivity possible on Twitter is often stressed as an important difference from one-way communication media such as TV. Although studies on parasocial interactions with athletes on Twitter and in the domain of social media marketing have shown that interactions by an athlete or brand with followers are beneficial for the development of parasocial interaction (Frederick, Lim, Clavio, \& Walsh, 2012; Labrecque, 2014), the current research showed that ambient intimacy can also develop in the absence of these interactions. This further shows that ambient intimacy is different from interpersonal relationships that often require interactions from both sides. Instead, the development of ambient intimacy resembles more the phenomenon of one-sided parasocial relationships, in which the interaction from the persona is not as important (Horton \& Wohl, 1956).

The findings for target-level ambient intimacy and disclosure intimacy contribute to the discussion of the role of intimate public self-disclosure on social media in relationship formation. Bazarova (2012) proposed that broadcasting intimate self-disclosure online is often perceived as inappropriate. In this study, we found that participants treated most of the tweets from their followees as appropriate. Under these circumstances, a higher level of perceived disclosure intimacy was found to be positively correlated to the development of ambient intimacy, which is in line with previous findings (Altman \& Taylor, 1973; Rains et al., 2014; Utz, 2015b). Perhaps, similar to the results in Cozby's (1972) study, it is possible to observe a reverse U-shaped relationship between perceived disclosure intimacy and ambient intimacy: A certain level of disclosure intimacy is good for promoting ambient intimacy, but highly intimate self-disclosure, when perceived as inappropriate, would probably backfire (Bazarova, 2012).

Interestingly, the perceived entertainment value was found to be the most substantial predictor of ambient intimacy. This is in line with Utz's (2015b) findings that, compared to other predictors such as perceived message intimacy and positivity, perceived entertainment value played a better role in predicting a feeling of connection. In addition, the perceived information value of tweets also contributed to the development of ambient intimacy. For ambient awareness, a slightly different picture emerged: The information value was a better predictor than the entertainment value.

Taken together, the three effects of message characteristics have theoretical implications for the development and maintenance of relationships on social media. Traditionally, intimacy of self-disclosure has been considered the main driver of relationship formation (Altman \& Taylor, 1973). On social media, disclosure intimacy is still important for ambient intimacy, but only when perceived as appropriate. Miller (2008) proposed that information might be treated as a commodity on social media and has a relationship-building function. The present results indicate that the entertainment value of posts is also a commodity that predicts relationship building on social media. 


\section{Practical Implications}

The study also has practical implications for knowledge sharing in professional settings. The concept of ambient awareness has received more attention recently in the domain of enterprise social media. This research has shown that regularly skimming updates can help build a cognitive representation of who-knows-what in the company; it is an important precondition for successful knowledge exchange (Leonardi \& Meyer, 2015). However, research on organizational knowledge sharing has shown that people prefer to turn to their strong ties, even if their weak ties have more valuable information, because they trust their strong ties more (Levin \& Cross, 2004). Next to the cognitive process of knowing-who-knows what, an emotional process is needed. Our results point to ambient intimacy as this emotional process: A practical implication for organizations is thus to allow for informal, entertaining communication on enterprise social media to stimulate trust-building processes.

\section{Limitations}

Inevitably, this study has several limitations. First, as this was a cross-sectional survey, it was not possible to determine causality. All correlations that were revealed in our analysis could be interpreted in both directions. For example, we cannot exclude the possibility that because the participants felt close to the target, they treated the target's tweets as more intimate or more entertaining. Future studies could use an experimental design to explore the effect of disclosure intimacy on the feeling of closeness. Second, we used only a single-item subjective measure for message characteristics, which could be attributable to objective differences and psychological factors. Future studies could use more items to increase reliability. It is also plausible to get an objective measure of disclosure intimacy by using sentiment analysis. Another improvement that could be made is to reduce the priming effect in the measurement of general-level ambient intimacy. This measurement was started with a sentence indicating that it is possible to have ambient intimacy, thus priming participant beliefs in a particular direction. Last, the participants in this sample were not as committed; thus, that we had to drop several participants who failed the attention check. Given the small effect size for certain correlations (such as coefficients for perceived intimacy and perceived information value), there was a relatively high likelihood of having a Type II error.

\section{Conclusion}

To conclude, the present paper provides fresh insights into the phenomenon of ambient intimacy: We theoretically distinguished the concepts of ambient intimacy from ambient awareness, examined the degree of ambient intimacy experienced by Twitter users, and thoroughly discussed how various message characteristics and one-sided interaction are associated with the development of ambient intimacy and awareness. We learned from this study that ambient intimacy can be developed after the frequent exposure of tweets, especially when the tweets were perceived as entertaining, intimate, and informative; ambient intimacy is also highly associated with one-sided interaction with the target. However, ambient intimacy is not a large experience that can be experienced by anyone and can be developed toward anyone. As social media plays an important role in lubricating social interactions (Leonardi \& Meyer, 2015), more studies are needed to investigate the antecedents and consequences of ambient intimacy.

\section{Acknowledgement}

The research leading to these results has received funding from the European Research Council under the European Union's Seventh Framework Programme (FP7/2007-2013) / ERC grant agreement no. 312420.

\section{Note}

1. No existing scale is suitable for capturing the concept of ambient intimacy in the context of social media: Scales such as Inclusion of Other in the Self-Scale (IOS; Aron, Aron, \& Smollan, 1992), the Relationship Closeness Inventory (RCl; Berscheid, Snyder, \& Omoto, 1989), and the Unidimensional Relationship Closeness Scale (URCS; Dibble, Levine, \& Park, 2012) fit better with measuring a feeling of closeness in the context of offline intimate relationships; whereas scales such as the Parasocial Interaction Scale (PSI; A. M. Rubin, Perse, \& Powell, 1985), 
the Experience of Parasocial Interaction Scale (EPSI; Hartmann \& Goldhoorn, 2011), the Parasocial Relationship Scale (PSR; Tuchakinsky, 2010), and the Audience Persona Interaction Scale (API; Auter \& Palmgreen, 2000) were designed for measuring parasocial interactions and relationships in traditional media settings (most often TV viewing).

We decided to capture the phenomenon of ambient intimacy by combining the measure of propinquity and the formation of a positive parasocial relationship: Propinquity can be measured with a feeling of closeness, and the formation of a positive parasocial relationship can be indicated by the likelihood of parasocial interaction during and after exposure. Some items for measuring parasocial interaction were adapted in order to fit the context of social media.

\section{References}

Altman, I., \& Taylor, D. A. (1973). Social penetration: The development of interpersonal relationships. Holt, Rinehart \& Winston.

Aron, A., Aron, E. N., \& Smollan, D. (1992). Inclusion of Other in the Self Scale and the structure of interpersonal closeness. Journal of Personality and Social Psychology, 63, 596-612. http://dx.doi.org/10.1037/0022-3514.63.4.596

Auter, P. J., \& Palmgreen, P. (2000). Development and validation of a parasocial interaction measure: The audience-persona interaction scale. Communication Research Reports, 17, 79-89.

http://dx.doi.org/10.1080/08824090009388753

Baruh, L., \& Cemalcılar, Z. (2015). Rubbernecking effect of intimate information on Twitter: When getting attention works against interpersonal attraction. Cyberpsychology, Behavior, and Social Networking, 18, 506-513. http://dx.doi.org/10.1089/cyber.2015.0099

Bazarova, N. N. (2012). Public intimacy: Disclosure interpretation and social judgments on Facebook. Journal of Communication, 62, 815-832. http://dx.doi.org/10.1111/j.1460-2466.2012.01664.x

Berscheid, E., Snyder, M., \& Omoto, A. M. (1989). The Relationship Closeness Inventory: Assessing the closeness of interpersonal relationships. Journal of Personality and Social Psychology, 57, 792-807.

http://dx.doi.org/10.1037/0022-3514.57.5.792

Brinker, S. (2009). Twitter and the law of propinquity. Retrieved from http://chiefmartec.com/2009/01/twitterand-the-law-of-propinquity/

Buechel, E., \& Berger, J. (2016). Motivations for consumer engagement with social media. In C. Dimofte, C. Haugtvedt, \& R. Yalch (Eds.), Consumer Psychology in a social media world (p. 17). New York, NY: Routledge.

Chen, G. M. (2011). Tweet this: A uses and gratifications perspective on how active Twitter use gratifies a need to connect with others. Computers in Human Behavior, 27, 755-762. http://dx.doi.org/10.1016/j.chb.2010.10.023

Collins, N. L., \& Miller, L. C. (1994). Self-disclosure and liking: A meta-analytic review. Psychological Bulletin, 116, 457-475. http://dx.doi.org/10.1037/0033-2909.116.3.457

Cozby, P. C. (1972). Self-disclosure, reciprocity and liking. Sociometry, 35, 151-160.

http://dx.doi.org/10.2307/2786555

Dibble, J. L., Hartmann, T., \& Rosaen, S. F. (2016). Parasocial interaction and parasocial relationship: conceptual clarification and a critical assessment of easures. Human Communication Research, 42,21-44.

http://dx.doi.org/10.1111/hcre.12063 
Dibble, J. L., Levine, T. R., \& Park, H. S. (2012). The Unidimensional Relationship Closeness Scale (URCS): Reliability and validity evidence for a new measure of relationship closeness. Psychological Assessment, 24, 565-572.

http://dx.doi.org/10.1037/a0026265

Ellison, N. N. B., Steinfield, C., \& Lampe, C. (2007). The benefits of Facebook "friends": Social capital and college students' use of online social network sites. Journal of Computer-Mediated Communication, 12, 1143-1168. http://dx.doi.org/10.1111/j.1083-6101.2007.00367.x

Festinger, L., Schachter, S., \& Back, K. (1950). The spatial ecology of group formation. Social Pressure in Informal Groups, 141-161.

Frederick, E. L., Lim, C. H., Clavio, G., \& Walsh, P. (2012). Why we follow: An examination of parasocial interaction and fan motivations for following athlete archetypes on Twitter. International Journal of Sport Communication, 5(2010), 481-502.

Grieve, R., Indian, M., Witteveen, K., Tolan, G. A., \& Marrington, J. (2013). Face-to-face or Facebook: Can social connectedness be derived online? Computers in Human Behavior, 29, 604-609.

http://dx.doi.org/10.1016/j.chb.2012.11.017

Hartmann, T., \& Goldhoorn, C. (2011). Horton and Wohl revisited: Exploring viewers' experience of parasocial interaction. Journal of Communication, 61, 1104-1121. http://dx.doi.org/10.1111/j.1460-2466.2011.01595.x

Horton, D., \& Wohl, R. R. (1956). Mass communication and para-social interaction; observations on intimacy at a distance. Psychiatry, 19, 215-229. Retrieved from http://www.participations.org/volume 3/issue 1/3_01_hortonwohl.htm

Johnson, P. R., \& Yang, S.-U. (2009). Uses and gratifications of Twitter: An examination of user motives and satisfaction of Twitter use. In In Communication Technology Division of the annual convention of the Association for Education in Journalism and Mass Communication. Boston, MA.

Kaplan, A. M. (2012). If you love something, let it go mobile: Mobile marketing and mobile social media 4x4. Business Horizons, 55, 129-139. http://dx.doi.org/10.1016/j.bushor.2011.10.009

Kelly, R. (2009). Twitter Study - August 2009. Pear Analytics. http://dx.doi.org/10.1016/S1361-3723(09)70038-7

Korzenny, F. (1978). A theory of electronic propinquity: Mediated communication in organizations. Communication Research, 5, 3-24. http://dx.doi.org/10.1177/009365027800500101

Labrecque, L. I. (2014). Fostering consumer-brand relationships in Social Media environments: The role of parasocial interaction. Journal of Interactive Marketing, 28, 134-148.

http://dx.doi.org/10.1016/j.intmar.2013.12.003

Leonardi, P. M., \& Meyer, S. R. (2015). Social media as social lubricant: How ambient awareness eases knowledge transfer. American Behavioral Scientist, 59, 10-34. http://dx.doi.org/10.1177/0002764214540509

Levin, D. Z., \& Cross, R. (2004). The strength of weak ties you can trust: The mediating role of trust in effective knowledge transfer. Management Science, 50, 1477-1490. http://dx.doi.org/10.1287/mnsc.1030.0136

Levordashka, A., Lin, R., \& Utz, S. (2015). Ambient awareness: Interpersonal knowledge in online social networks. In International Communication Association.

Levordashka, A., \& Utz, S. (2016). Ambient awareness: From random noise to digital closeness in online social networks. Computers in Human Behavior, 60, 147-154. http://dx.doi.org/10.1016/j.chb.2016.02.037 
Miller, V. (2008). New Media, Networking and Phatic Culture. Convergence, 14, 387-400.

http://dx.doi.org/10.1177/1354856508094659

Nichols, A. L., \& Webster, G. D. (2013). The single-item need to belong scale. Personality and Individual Differences, 55, 189-192. http://dx.doi.org/10.1016/j.paid.2013.02.018

Oppenheimer, D. M., Meyvis, T., \& Davidenko, N. (2009). Instructional manipulation checks: Detecting satisficing to increase statistical power. Journal of Experimental Social Psychology, 45, 867-872.

http://dx.doi.org/10.1016/j.jesp.2009.03.009

Perse, E. M., \& Rubin, R. B. (1989). Attribution in social and parasocial relationships. Communication Research, 16, 59-77. http://dx.doi.org/10.1177/009365089016001003

Rains, S. A., Brunner, S. R., \& Oman, K. (2014). Self-disclosure and new communication technologies: The implications of receiving superficial self-disclosures from friends. Journal of Social and Personal Relationships, 1 20. http://dx.doi.org/10.1177/0265407514562561

Reichelt, L. (2007). Ambient Intimacy. Disambiguity. Retrieved from http://www. disambiguity.com/ambientintimacy/

Riedl, C., Köbler, F., Goswami, S., \& Krcmar, H. (2013). Tweeting to feel connected: A model for social connectedness in online Social Networks. International Journal of Human-Computer Interaction, 29, 670-687. http://dx.doi.org/10.1080/10447318.2013.768137

Rubin, A. M., Perse, E. M., \& Powell, R. a. (1985). Loneliness, parasocial interaction, and local television news viewing. Human Communication Research, 12, 155-180. http://dx.doi.org/10.1111/j.1468-2958.1985.tb00071.x

Rubin, R. B., \& McHugh, M. P. (1987). Development of parasocial interaction relationships. Journal of Broadcasting \& Electronic Media, 31, 279-292. http://dx.doi.org/10.1080/08838158709386664

Schramm, H., \& Hartmann, T. (2008). The PSI-Process Scales. A new measure to assess the intensity and breadth of parasocial processes. Communications, 33, 385-402. http://dx.doi.org/10.1515/COMM.2008.025

Spector, P. E., Van Katwyk, P. T., Brannick, M. T., \& Chen, P. Y. (1997). When two factors don't reflect two constructs: How item characteristics can produce artifactual factors. Journal of Management, 23, 659-677. http://dx.doi.org/10.1177/014920639702300503

Sprecher, S., Treger, S., \& Wondra, J. D. (2012). Effects of self-disclosure role on liking, closeness, and other impressions in get-acquainted interactions. Journal of Social and Personal Relationships, 1-18. http://dx.doi.org/10.1177/0265407512459033

Thompson, C. (2008). Brave new world of digital intimacy. New York Times, 1-9. Retrieved from http://individual.utoronto.ca/kreemy/proposal/07.pdf

Treger, S., Sprecher, S., \& Erber, R. (2013). Laughing and liking: Exploring the interpersonal effects of humor use in initial social interactions. European Journal of Social Psychology, 43, 532-543.

http://dx.doi.org/10.1002/ejsp.1962

Tuchakinsky, R. (2010). Para-romantic love and para-friendships: Development and assessment of a multiple parasocial relationships scale. American Journal of Media Psychology, 3, 73-94.

Utz, S. (2015a). Is LinkedIn making you more successful? The informational benefits derived from public social media. New Media \& Society . Advanced online publication. http://dx.doi.org/10.1177/1461444815604143 
Utz, S. (2015b). The function of self-disclosure on social network sites: Not only intimate, but also positive and entertaining self-disclosures increase the feeling of connection. Computers in Human Behavior, 45, 1-10.

http://dx.doi.org/10.1016/j.chb.2014.11.076

Zajonc, R. B. (1968). Attitudinal effects of mere exposure. Journal of Personality and Social Psychology, 9(2p2), 1-27. http://dx.doi.org/10.1037/h0025848

\section{Correspondence to:}

Ruoyun Lin

Leibniz-Institut für Wissensmedien

Schleichstraße 6

72076 Tübingen

Germany

Email: r.lin(at)iwm-tuebingen.de

\section{About authors}

Ruoyun Lin is a PhD student at the Social Media Group at Leibniz-Institut für Wissensmedien, Germany. Her research interests focus on various effects of social media usage, with special emphasis on self-disclosure, wellbeing, social capital, emotional contagion, social comparison, and trust-(re)building. She studied Innovation Sciences at Eindhoven University of Technology in the Netherlands (MSc, with great appreciation, 2013).

Ana Levordashka is a PhD student at the Social Media Group at Leibniz-Institut für Wissensmedien, Germany. She studied integrated social and cognitive psychology at Jacobs University Bremen (B.A. in 2011) and completed a research master in social psychology at VU Amsterdam in 2013.

Sonja Utz is a professor for communication via social media at University of Tübingen, Germany. She is head of the research lab social media at Leibniz-Institut für Wissensmedien. Her research focuses on the effects of social media use in interpersonal and professional settings. 